\title{
Brushless DC Motor Speed Control Using Single Input Fuzzy PI Controller
}

\author{
N. N. Baharudin, S. M. Ayob \\ School of Electrical Engineering, Faculty of Engineering, Universiti Teknologi Malaysia, Malaysia
}

\begin{tabular}{|c|c|}
\hline Article Info & ABSTRACT \\
\hline & \multirow{9}{*}{$\begin{array}{l}\text { Brushless DC (BLDC) motor is more reliable than classic DC motor with } \\
\text { higher efficiency. Commonly used conventional linear controller such as PI, } \\
\text { PID and PD controller. FLC is considered a replacement to conventional } \\
\text { controller due to advantages on non-linear system. Hybrid controller e.g } \\
\text { Fuzzy PI controller is developed to cope with drawback of both controller. } \\
\text { Simplification of FLC in previous study is the pioneer of the idea of } \\
\text { proposed method. Single-Input Fuzzy PI Controller (SIFPIC) is a hybrid } \\
\text { controller that combines advantages of linear PI controller and fuzzy } \\
\text { controller in one control structure. Since it is a single input based fuzzy } \\
\text { controller, it yields simpler design and tuning process. Simulation is done } \\
\text { using MATLAB/Simulink and the performance is observed through speed } \\
\text { response under several conditions namely constant speed, changing seed and } \\
\text { changing load torque. The performance of SIFPIC is compared with } \\
\text { conventional PI and fuzzy PI controller. SIFPIC is as expected produced a } \\
\text { response similar with the conventional fuzzy PI controller with both fuzzy } \\
\text { based controller produce response with better dynamic. }\end{array}$} \\
\hline Received Sep 17, 2018 & \\
\hline Revised Okt 8, 2018 & \\
\hline Accepted Oct 18, 2018 & \\
\hline Keyword: & \\
\hline Brushless dc motor & \\
\hline PI controller & \\
\hline Fuzzy logic control & \\
\hline Speed control & \\
\hline
\end{tabular}

Copyright $(2) 2018$ Institute of Advanced Engineering and Science. All rights reserved.

\section{Corresponding Author:}

Shahrin Md Ayob

School of Electrical Engineering

Faculty of Engineering

Universiti Teknologi Malaysia, 81310 UTM Skudai, Malaysia.

Email: e-shahrin@utm.my

\section{INTRODUCTION}

Electric drives uses an electric motor as its prime movers and considered as the best solution to the problem of transfering the energy from its initial place to the demand point and converting it to its final form [1]. Electric motors in constant speed drives do not required to be controlled unless for starting, stopping or protection though at some point speed and torque must matched to the need of mechanical load [2]. Of all various type of electric motors, Brushless DC motor comes with better speed torque characteristic, noiseless operation and higher speed range compared to brushed DC and induction motor [3].

In 1990's, several conventional linear controller such as PI, PD and PID controller are used to control BLDC motor drive [4]. However, non-linear system basically required a variable-speed operation in which PI controller unable to cope due to its limitation in single operating point $[5,6]$ while PD and PID usually avoided in Power Electronic because of its tendency to amplify the ripple. Apart from that, PI controller required a mathematical model that is hard to obtain especially for non-linear system [5]. Thus, to cope with the nonlinearity of a system, nonlinear controllers are developed and proposed in form of sliding mode, neural network and fuzzy logic controller. Preferably sliding mode and FLC which both are nonmodel based controllers [7].

Fuzzy Logic controller is one type of artificial-intelligence method that based on an algorithm that can systematically convert the linguistic rules into automatic control scheme[8,9]. It has advantages of precise mathematical control and human-like decision making and ability to operate in broad range of 
operation[8-10]. The FLC basically derived from fuzzy set theory which was introduced by Zadeh in mid 1960's and much prefered than Sliding Mode controller which complex to design [7]. Unlike PI controller which can implemented a well-established design procedure such as bode-plot technique and Nyquist, yet at present there is no systematic procedure for FLC design. Hence, the stability and optimum performance is oftenly difficult to achieve [9, 11-13].

In a moment, there are many works that combine several controllers into one control structure. This type of controller is called hybrid controller. A study on benefits of hybrid controllers on system perfromance in general has been done previously that listed three expected benefits; performance that exceed classical linear or nonlinear smooth controller, performance that reflects multiple objectives and performance that respects state and control restraint [14]. In this paper, hybrid controller in discussion is Fuzzy PI controller; combination of FLC and PI controller. Fuzzy PI controller in general uses linear control theory applied by PI controller into Fuzzy control structure. This controller is capable to produce a performance similar to PI controller [15-19]. Modification can be done to the control surface of fuzzy in order to achieve better performance when dealt with non-linearity of the system [20].

Nonetheless, Fuzzy PI still suffer from lengthy design time cycle due to a lot of tuning parameters [7, 11, 20, 21]. This Paper proposed a simpler Fuzzy PI controller that capable of achieving a comparable performance as the conventional Fuzzy PI but with much lesser number fo rules and tuning parameters. This controller is known Single-Input Fuzzy PI Controller (SIFPIC) in which a new variable called distance, d is proposed as the only input variable to the controller. This is attained by applying signed-distance method in fuzzy part of the controller. The derivation of the single-input was first introduced by [22] in a FLC for a basic pendulum system. The control structure and model of BLDC motor drive will be built in MATLAB/Simulink. Simulation under load and no load condition will be run to justify the performance.

\section{THE PROPOSED SIFPIC CONTROLLER}

In recent years, researchers leaning toward hybrid controllers for more improved performance. The merging of Fuzzy Logic Controller (FLC) and PI controller is among those hybrid controllers called Fuzzy PI controller [23]. The standard fuzzy PI controller has follows the original design of FLC with 2 or more input variables. However, fuzzy Logic controller basically has suffers from a lengthy time cycle with a lot of tuning parameters. As mention previously, FLC also has difficulty in achieving consistent optimized performance and its major problem is it has no standard design procedure. As Fuzzy PI controller behavior is dependable on the number of rules and its input variable, the tuning process is rather complex and thus certain applications might not able to adapt the controller.

Logically, since the tuning process is complex due to many parameter and number of rules, thus the problem can be solved by reducing it. As proposed by [22], using signed-distance method to mathematically reduced the parameter and introduced a new sole input variable, distance where automatically reduced the number of rules. The control surface of the controller will be reduced to one dimension surface instead of two-dimension in which it can approximately be a piecewise linear. Implement the proposed single input fuzzy into fuzzy PI controller as done in [19] is the proposed control method for motor drive in this research.

\subsection{The Signed-Distance Method}

As proposed in [22], the number of rules can be greatly reduced by applying the signed distance method to efficiently lessen the number of inputs. In order to apply the proposed method, this paper used a rule table with a Toeplitz structure, in which the output membership function is the same in a diagonal line. Table 1 shows the rule table that exhibits Toeplitz structure where the diagonal line with ZERO membership function is the main diagonal line.

Table 1.The rule table with Toeplitz structure

\begin{tabular}{llllll}
\hline ElCE & NB & NS & Z & PS & PB \\
\hline NB & Z & NB & NB & NB & NB \\
NS & PS & $Z$ & NS & NB & NB \\
Z & PB & PS & Z & NS & NB \\
PS & PB & PB & PS & Z & NS \\
PB & PB & PB & PB & PB & Z \\
\hline
\end{tabular}


The distance, $\mathrm{d}$ represent the absolute distance from any points of the main diagonal line to any state of point perpendicular to it. The distance, $d$ also can be mathematically defined as in (1),

$$
d=\frac{\dot{e}+\lambda e}{\sqrt{1+\lambda^{2}}}
$$

Where and are theerror and change of error input, respectively. While represents the slope of the main ZERO diagonal line. The reduced rule table is presented in Table 2 in which the inputs are the diagonal lines from rule table in Table 1.

Table 2. Reduced rule table

\begin{tabular}{llllll}
\hline$d$ & $L_{N B}$ & $L_{N S}$ & $L_{Z}$ & $L_{P S}$ & $L_{P B}$ \\
\hline$u_{o}$ & $\mathrm{NB}$ & $\mathrm{NS}$ & $\mathrm{Z}$ & $\mathrm{PS}$ & $\mathrm{PB}$ \\
\hline
\end{tabular}

\subsection{The SIFPIC Control Structure}

The block diagram of the proposed method is shown in Figure 1 where (a) is the simplified structure of fuzzy PI while (b) is structure of a discrete PI controller [11]. SIFPIC can efficiently act as discrete PI controller as the control surface; $\Psi$ is set at unity gain.

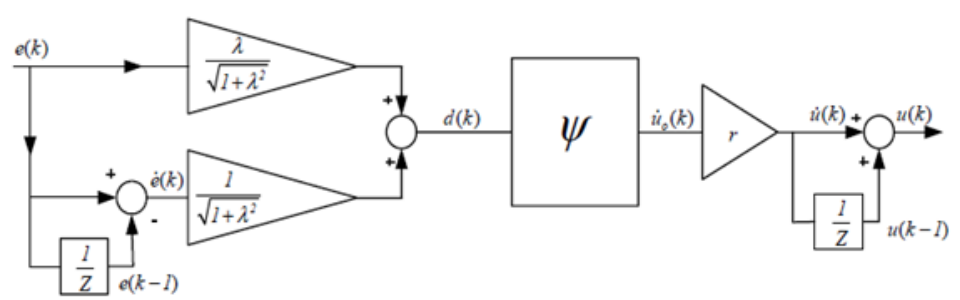

Figure 1(a). The SIFPIC control structure

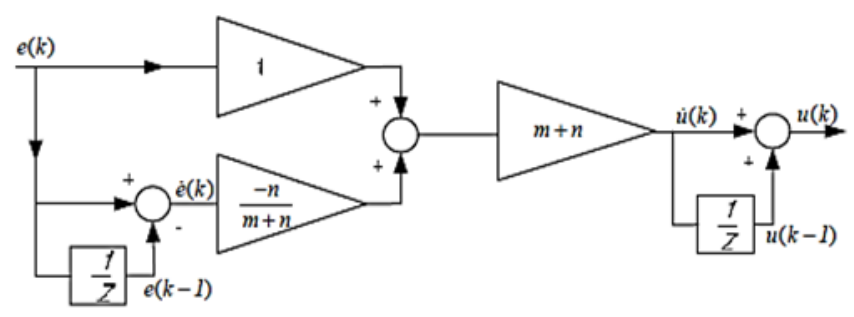

Figure 1(b). The discrete PI Control Structure

To design the discrete PI controller as Figure 1(b), consider the transfer function of PI controller in continuous time expressed as (2)

$C(s)=K_{i}\left[\frac{\left(\left(K_{p} / K_{i}\right) s+1\right)}{s}\right]$ 
Using bilinear transformation as in (3)

$$
s=2 T_{s}\left[\frac{Z}{Z+1}\right]
$$

Substitute (3) in (2), an equivalent discrete transfer function of PI controller is expressed in (4)

$$
C(z)=\left(\frac{m z+n}{z 1}\right)
$$

The parameter $\mathrm{m}$ and $\mathrm{n}$ are obtain through (5) and (6) with Ts as the sampling time [4].

$$
\begin{aligned}
& m=K_{i}\left(\frac{K_{p}}{K_{i}}+\frac{T_{s}}{2}\right) \\
& n=K_{i}\left(\begin{array}{ll}
\frac{T_{s}}{2} & \frac{K_{p}}{K_{1}}
\end{array}\right)
\end{aligned}
$$

In case of small signal disturbance, for SIFPIC to achieve best performance as linear discrete PI controller, the parameter $\mathrm{m}$ and $\mathrm{n}$ is obtained by setting the gain at unity. Thus parameters $\mathrm{r}$ and $\lambda$ can be written as in (7) and (8) which derived in $[4,10]$ by comparing the output equation of both SIFPIC and discrete PI controller.

$$
\begin{aligned}
r & =m+n \\
& =\left(\frac{m+n}{n}\right)
\end{aligned}
$$

As for large signal disturbance, the gain of the control surface is supposed to be higher than unity as to fasten the control response. This way it can solved the issues of lengthy design time cycle that the conventional controller had suffered.

\subsection{Representation of Fuzzy Control Surface as Piecewise Linear Approximation}

The graphical representation of the relationship between inputs and outputs of a system is called control surface. Control surface of a conventional FLC is mapping in three-dimensional with 2 inputs variable; error and change of error. It can come in various shapes including linear as it dependable on how the parameters are tuned. Tuning parameters consist of membership functions, percentage of its overlapping, inference method, fuzzificatioan and defuzzification process. As mention before, FLC faced issue of achieving optimum performance with no established standard design procedure as solely depend on control surface tuning. Figure 2(a) shows example of control surface with low degree of non-linearity. Figure 2(b) shows example of control surface with high degree of non-linearity. 


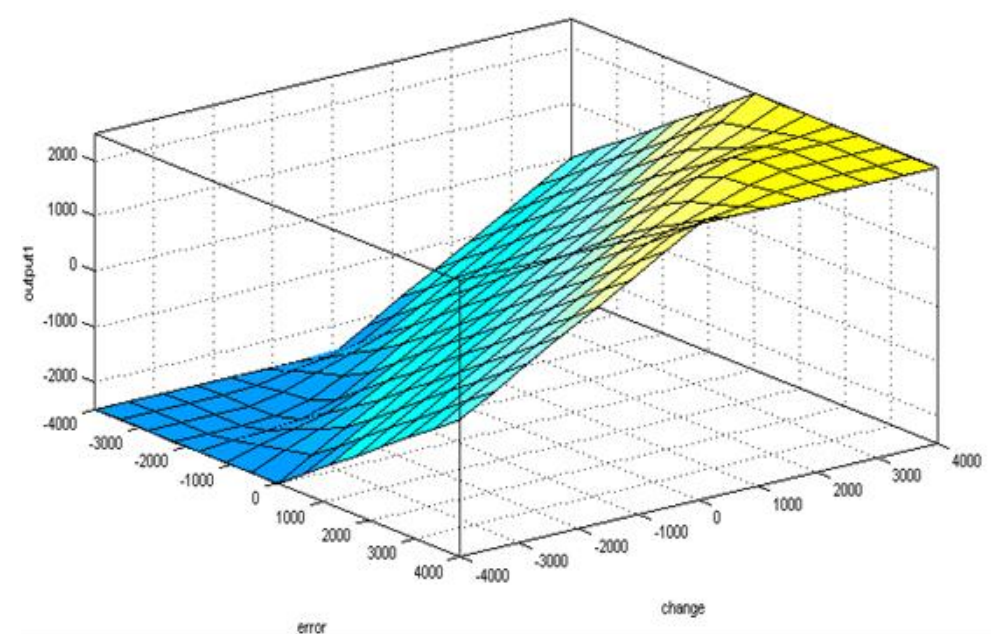

(a)

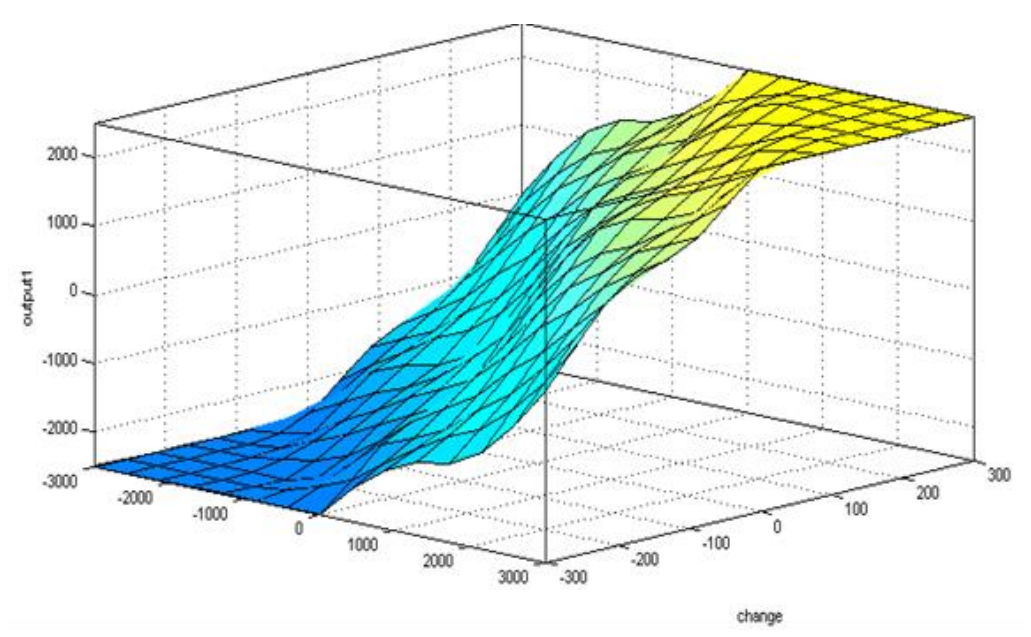

(b)

Figure 2. (a) Example of control surface with low degree of non-linearity, (b) Example of control surface with high degree of non-linearity

For SIFPIC, the control surface can be mapping in one dimension as it has only two variables; input and output. The control surface is developed by different sets of input and output membership functions combinations [9]. Changing the peak location of input membership functions and the location of the singleton output membership functions to be in unequal spaces will produce a non-linear control surface. Previous study has shown that a combination of triangular input sets and singleton output sets gives the best approximation of linear surface.

Figure 3(a) illustrates an approximated linear control surface generated by an evenly arranged input and output sets and the equivalent FLC control surface obtained through fuzzification, rules inferences and defuzzification process. Following that, Figures 3(b), (c) and (d) show the modified control surface when the input and output set of membership functions are altered. 


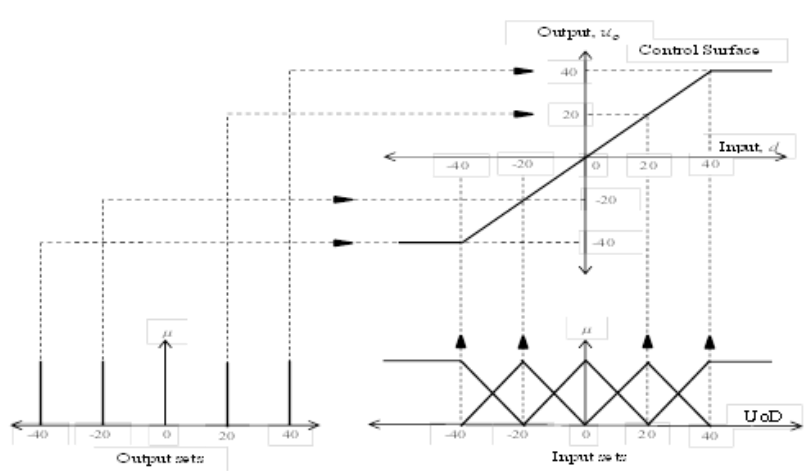

(i)

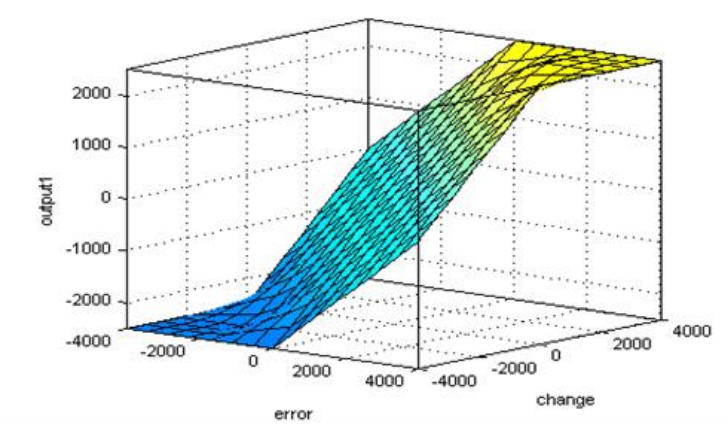

(ii)

Figure 3 (a). Linear control surface with evenly adjusted input and output membership function; (i) Approximate linear control surface (ii) Original fuzzy control surface with two input variable

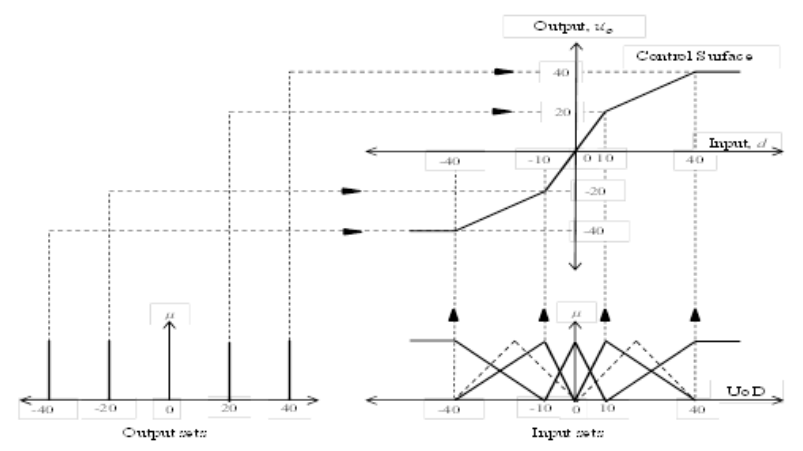

(i)

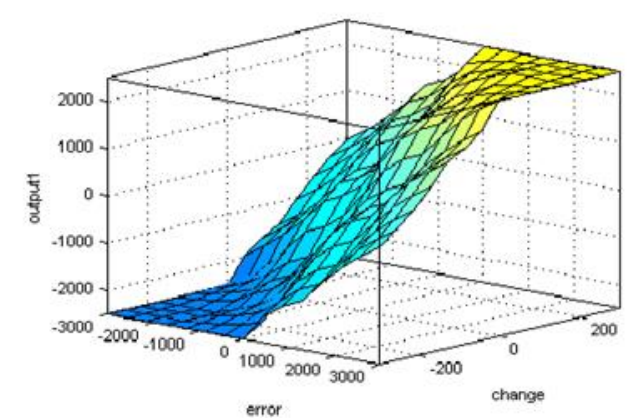

(ii)

Figure 3(b). Non-linear control surface with adjusted peak location input membership function; (i) Approximate linear control surface (ii) Original fuzzy control surface with two input variable 


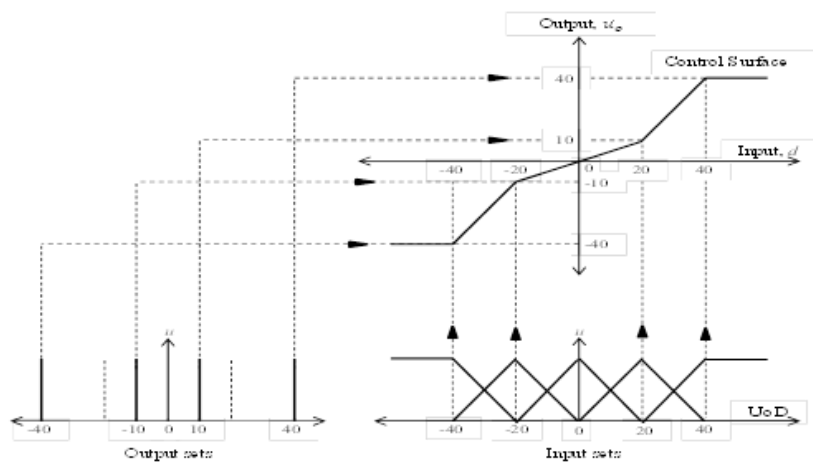

(i)

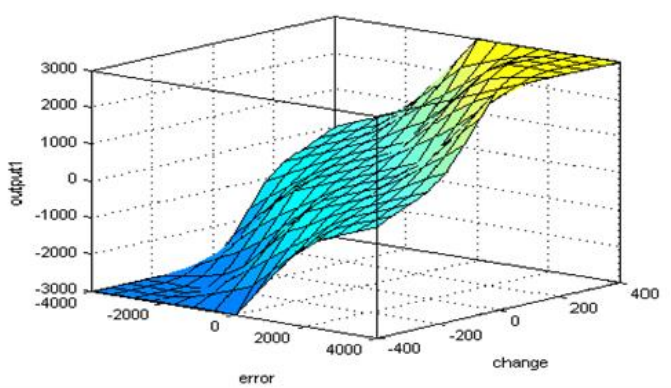

(ii)

Figure 3(c). Non-linear control surface with adjusted location of singleton output membership function; (i) Approximate linear control surface (ii) Original fuzzy control surface with two input variable

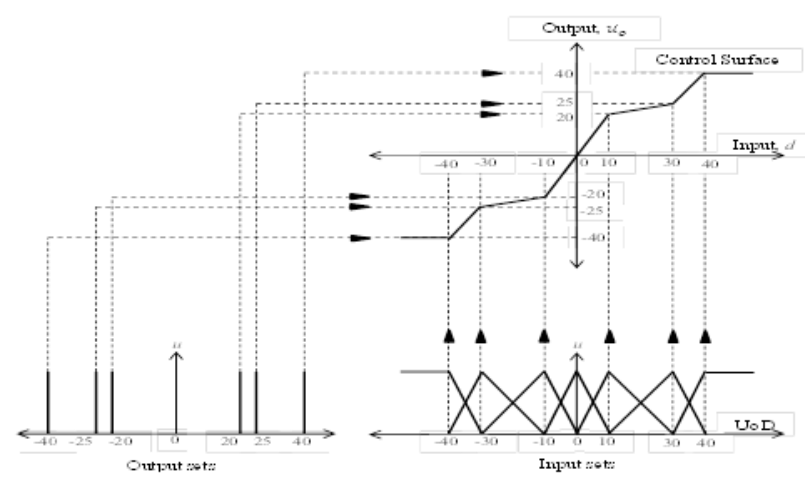

(i)

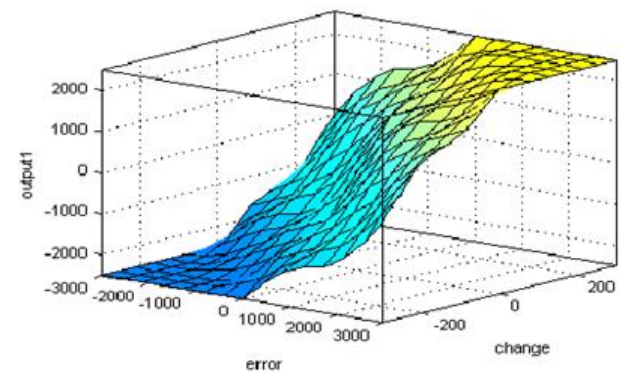

(ii)

Figure 3(d). Non-linear control surface with additional input and output membership function in uneven arrangement; (i) Approximate linear control surface (ii) Original fuzzy control surface with two input variable 


\section{RESEARCH METHODOLOGY}

The proposed SIFPIC controller is employed to control the speed of the BLDC motor. The control structure of BLDC motor drive is built up as in Figure 4. The motor is fed-up by a three-phase inverter with $48 \mathrm{~V}$ DC of input voltag. It has two closed control loops which is the inner loop is to control the current to generate the PWM inverter signals while the outer loop control the speed of the motor. The loops are arranged in cascaded form.

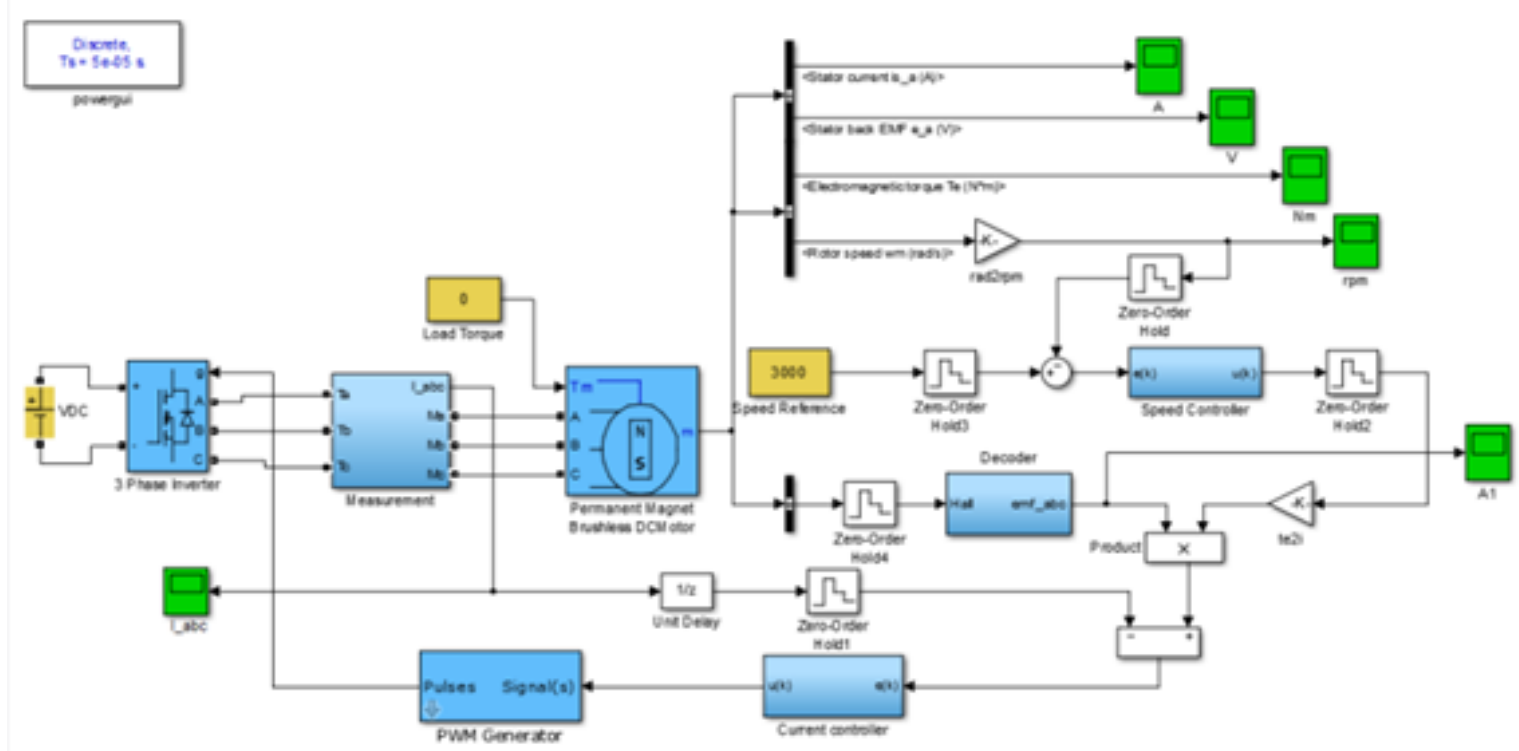

Figure 4. BLDC motor drive modeled in MATLAB/Simulink

The parameter of the motor drive system is summarized as in Table 3. The SIFPIC is designed to have both PI control performance behavior for small-signal disturbance but superior over PI controller for large-signal disturbance. For that, for distance input that is considered as small-signal area, the gain of the cpntrol surface is set to unity. For lare-signal disturbance, where the control performance should be faster than the response of PI controller, the gain is set at higher value than unity. However, the value selection is done via heuristic approach. The following sections will describe step by step the design of the SIFPIC. The design of the controller is started with inner loop and then outer loop [19,20].

Table 3. Motor rating

\begin{tabular}{lc}
\hline Parameters & Value \\
\hline Rated Output Power & $660 \mathrm{~W}$ \\
Rated Current & $17.5 \mathrm{~A}$ \\
Rated Speed & $3000 \mathrm{rpm}$ \\
Rated Torque (cont.) & $2.1 \mathrm{Nm}$ \\
Peak Torque & $6.3 \mathrm{Nm}$ \\
Motor Torque Constant, $k_{t}$ & $0.118 \mathrm{Nm} / \mathrm{A}$ \\
Stator Resistance, $R_{s}$ & $0.16 \pm 10 \% \Omega$ \\
Stator Inductance, $L_{s}$ & $0.3 \pm 20 \% \mathrm{mH}$ \\
Moment of Inertia, J & $0.00024 \mathrm{kgm}{ }^{2}$ \\
Inverter Switching Frequency, $f_{s}$ & $20 \mathrm{kHz}$ \\
Current loop sampling time, $T_{s 2}$ & $25 \mu \mathrm{s}$ \\
Speed loop sampling time, $T_{s 2}$ & $50 \mu \mathrm{s}$ \\
\hline
\end{tabular}




\subsection{The Inner Control Loop Design}

The transfer function for the current loop is obtained using Sisotool with control bandwidth set at 1 $\mathrm{kHz}$ and phase margin of $45^{\circ}$. The transfer function is then converted into the equivalent discrete transfer function using bilinear transformation [4]. The equivalent transfer function of the current loop is

$C(z)=\left(\begin{array}{rl}0.211 z & 0.0063 \\ z & 1\end{array}\right)$

By Comparing the current loop transfer function of (9) with (4), thus the parameters of $\mathrm{m}$ and $\mathrm{n}$ values are obtained as 0.222 and 0.0063 , respectively.

\subsection{The Outer Control Loop Design}

The closed loop control bandwidth should be one order of magnitude lower than the inner loop bandwidth [24, 25]. Using the same procedure as the inner loop to obtain the transfer function but the bandwidth and phase margin is changed to $100 \mathrm{~Hz}$ and $60^{\circ}$ respectively. The discrete transfer function acquired is expressed as in (10). By comparing the speed loop transfer function of (10) with (4), then the parameter $\mathrm{m}$ and $\mathrm{n}$ are obtained as 0.765 and 0.065 , respectively.

$C(z)=\frac{0.765 z \quad 0.056}{z \quad 1}$

\subsection{Simulation}

In order to validate the viability of the proposed SIFPIC, BLDC controlled by the conventional FLC and discrete PI controller are simulated together. Figure 5(a) shows the control structure of proposed controller, which function as speed controller. The fuzzy control surface $\Psi$ for all input values is modeled using fuzzy toolbox. Figures 5(b) and 5(c) show the conventional FLC and discrete PI controller, respectively.

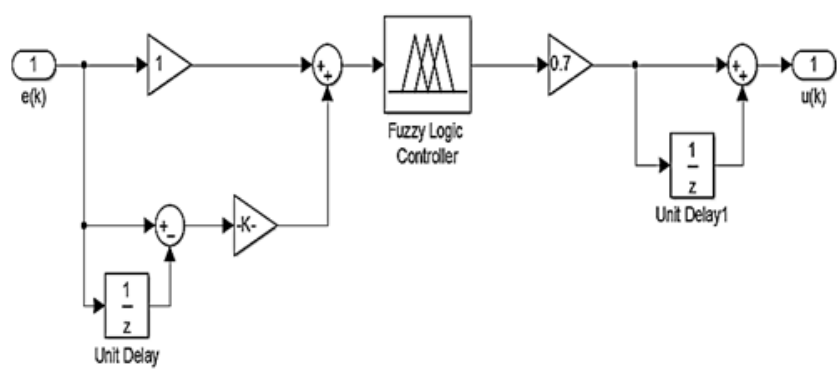

Figure 5(a). Control structure of SIFPIC

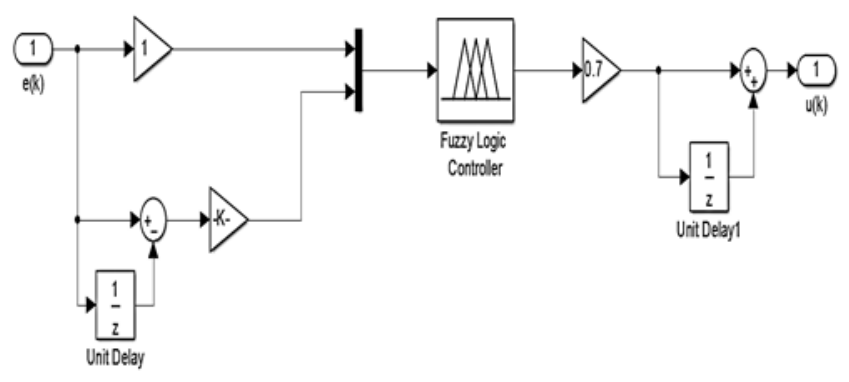

Figure 5(b). Control structure of conventional Fuzzy PI controller 


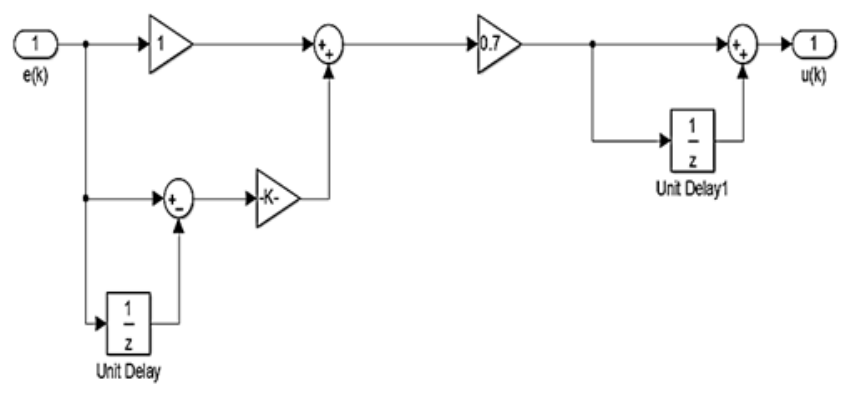

Figure 5(c). Control structure of discrete PI controller

Figures 6(a) and (b) show the control surface used for SIFPIC and conventional Fuzzy PI controller, respectively. The approximated control surface of SIFPIC is mapping in one dimension based on the control surface design for the conventional Fuzzy PI controller. As shown in previous section, different shapes of control surface are obtained by adjusting the location of peak of input and the singleton output membership function. This control surface is designed using trial and error method where the best performance is observed and chosen through different control surface design.

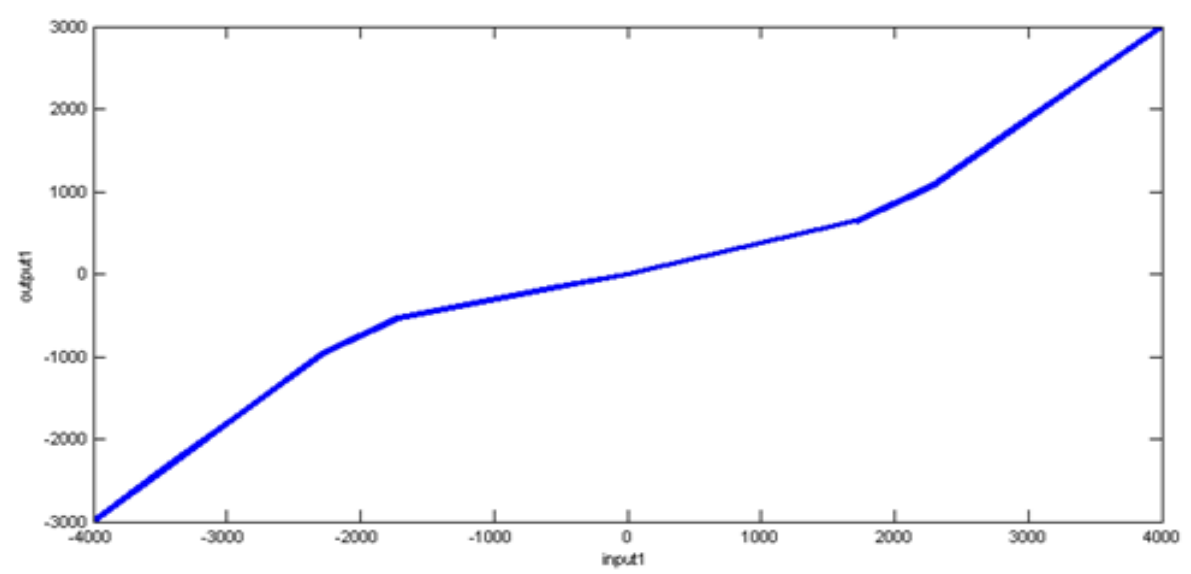

(a)

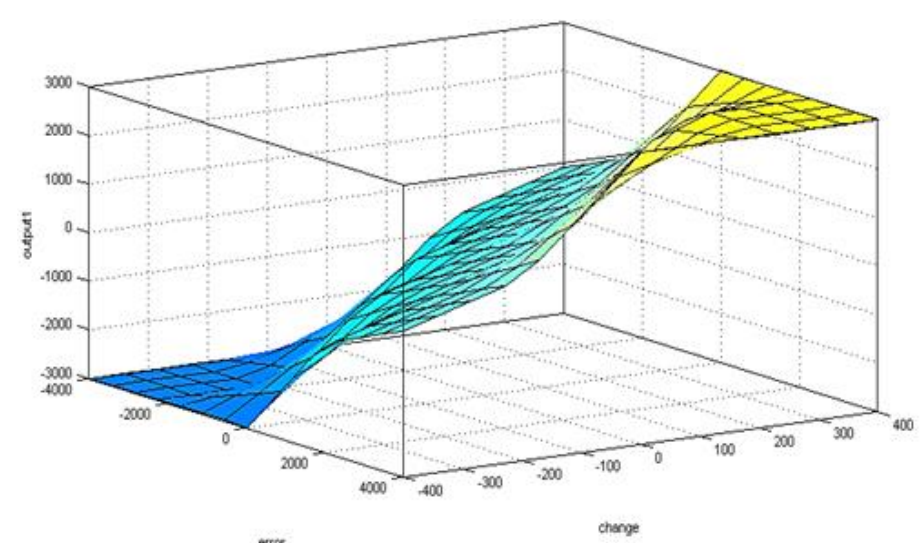

(b)

Figure 6. (a) Control surface of SIFPIC, (b) Control surface of conventional Fuzzy PI controller 


\section{RESULTS AND DISCUSSION}

The simulation result is observed through speed, current and torque response under several conditions such as no-load condition, constant and changing speed command and step changing in load torque. The performance of SIFPIC is compared with the performance of conventional PI and Fuzzy PI controller with same conditions.

Figure 7 shows the speed response of all three controllers with speed reference set at rated speed of $3000 \mathrm{rpm}$ under no load condition. SIFPIC is produced the same response as the conventional fuzzy PI controller and so does PI controller as in this case. This indicated that the system is running in small signal disturbance region where PI controller is at its best. $($ Red= SIFPIC, Blue= PI, Green= Fuzzy PI)

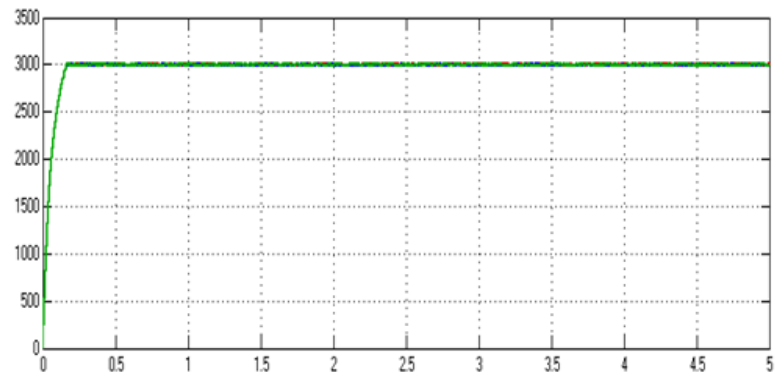

Figure 7. Speed response under no load condition

Figures 8(a)-(c) show the speed, current and torque response with step changing in speed reference, respectively. The speed is set initially at $3000 \mathrm{rpm}$ then decreased to $1000 \mathrm{rpm}$ (large-signal disturbance) at $2.5 \mathrm{~s}$ with $T_{L}=0 \mathrm{Nm}$ (no load condition). As shown in Figure 8(a), speed response of PI controller yields undershoot and oscillate for a few second before finally reaching its steady state condition (Red= SIFPIC, Blue= PI, Green $=$ Fuzzy PI).

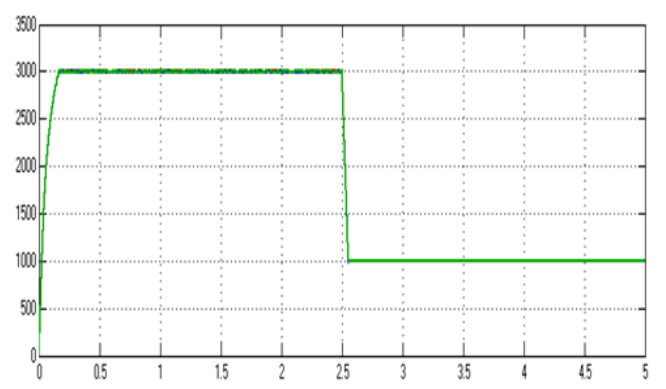

(a)

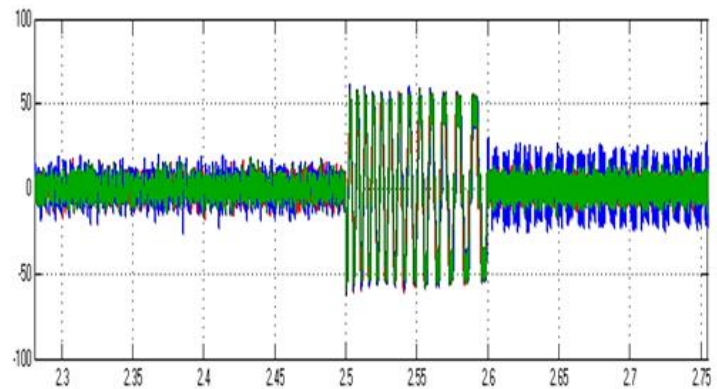

(b)

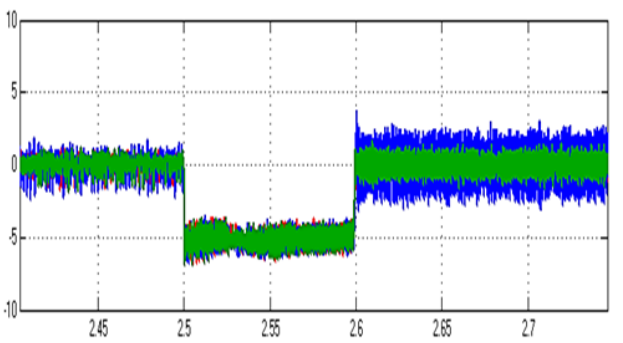

(c)

Figure 8. (a) Speed response with step speed command, (b) Current response with step speed command, (c) Torque response with step speed command 
From Figures 8(b) and (c), it is observed that PI controller produced higher ripple in both current and torque response while both SIFPIC and fuzzy PI controller exhibits smaller ripples. However, it is noted that all three controller take equal amount of recovery time which is in one seconds.

The BLDC motor drive speed response under a constant speed reference and load torque is presented in Figure 9. A load torque of $1 \mathrm{Nm}$ is applied throughout the simulation with constant speed command of 3000rpm. The value of the load torque is just randomly chosen as long it does not exceed the rated torque of the motor, which stated as $2.1 \mathrm{Nm}$. It can be seen that, the speed response under loading condition is the same with the response of no-load condition but with a few seconds slower settling time. This observation shows that constant load torque does not affect the speed performance of the motor under constant speed command.

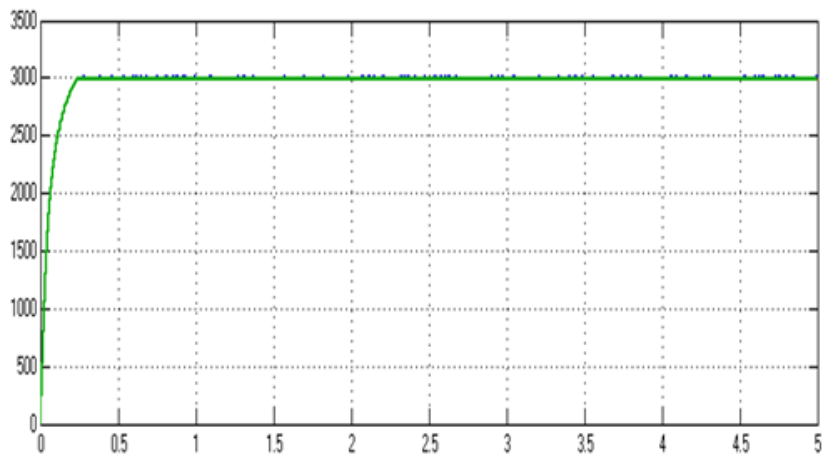

Figure 9. Speed response under loading condition

Figure 10(a)-(c) show the speed, current and torque response of the BLDC respectively. The motor drive is fed with step speed command under loading condition where a load torque of $1 \mathrm{Nm}$ is applied. The command speed is reduced to $1000 \mathrm{rpm}$ at $\mathrm{t}=2.5 \mathrm{~s}$ from the rated speed of $3000 \mathrm{rpm}$.

As illustrated in Figure 10(a), PI controller exhibits undershoots as the speed command reached $1000 \mathrm{rpm}$ and take longer time to recover to its steady state condition. Supposed that SIFPIC and fuzzy PI controlled have similar response however in this case, SIFPIC provides better response as fuzzy PI controller is slightly lagging as the speed is reduced. Current response shows in fFgure 10(b) that is under loading condition is a bit different compared to the response of no load condition. Still, PI controller does have higher current ripple than SIFPIC and fuzzy PI controller however its recovery time is slightly faster. Noted that all three controller did recover under under $1 \mathrm{~s}$ time which faster than response without load torque. Torque response shown in Figure 10(c) is similar with the response in Figure 8(c) but with faster recovery time, which took less than $1 \mathrm{~s}$.

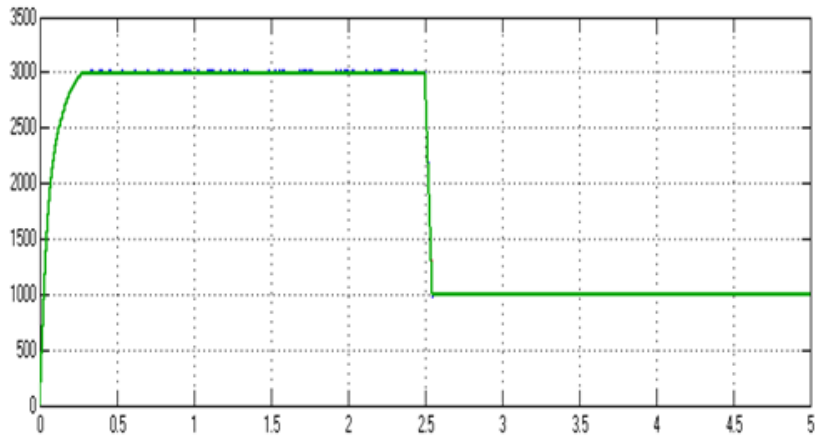

(a) 


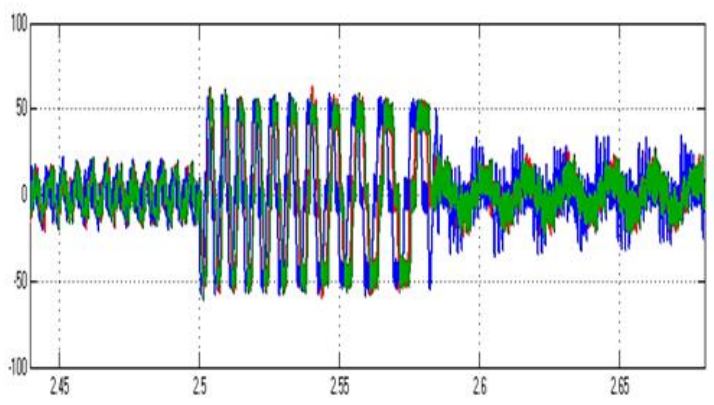

(b)

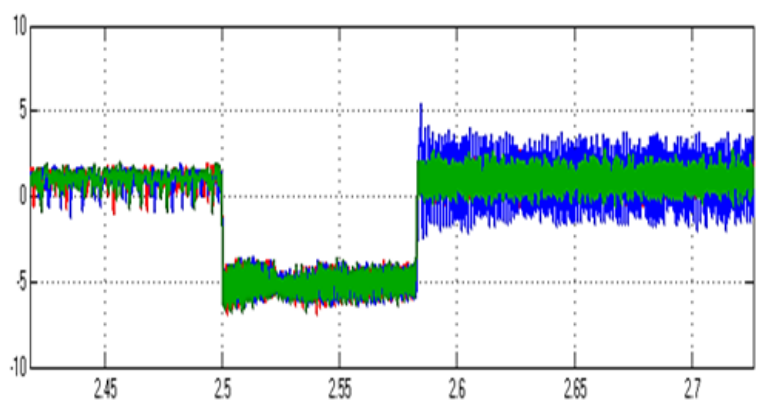

(c)

Figure 10. (a) Speed response with step speed command, (b) Current response with step speed command, (c) Torque response with step speed command

Speed, current and torque response under step load torque is recorded in Figures 11(a)-(c). The load torque of $1 \mathrm{Nm}$ is applied at $\mathrm{t}=1.5 \mathrm{~s}$ and the removed at $\mathrm{t}=2.5 \mathrm{~s}$. The speed response recorded a very small change when the load is applied but manage to track back to steady state condition. While current responses goes higher as load is applied and back to its original value as load is removed. (Red= SIFPIC, Blue $=$ PI, Green= Fuzzy PI)

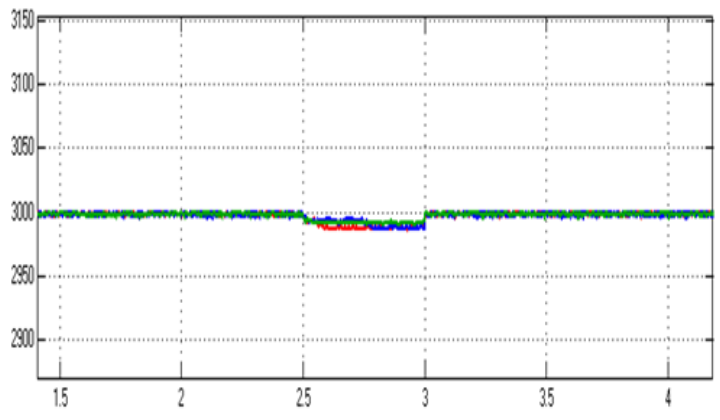

(a)

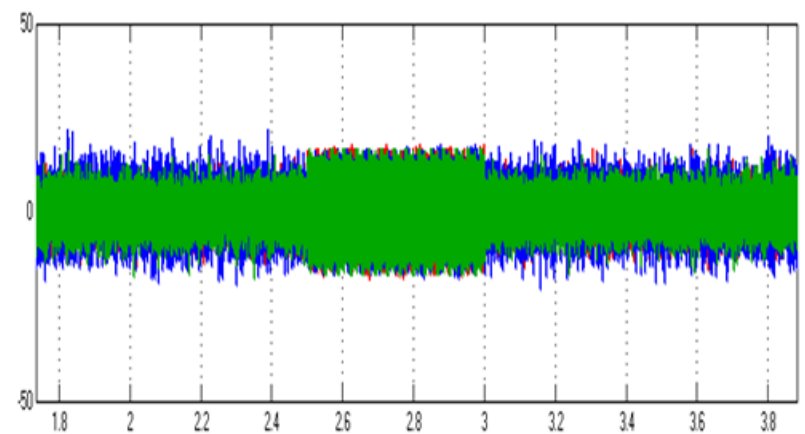

(b)

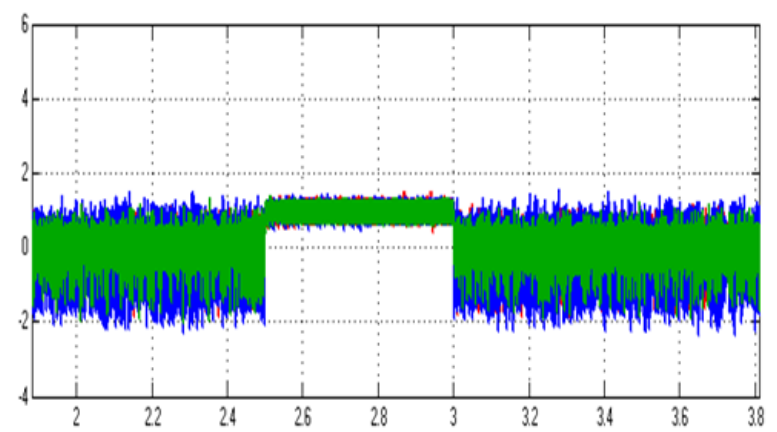

(c)

Figure 11. (a) Speed response under changing load condition, (b) Current response under changing load condition, (c) Torque response under changing load condition

\section{CONCLUSION}

This paper presents the design of the proposed Single Input Fuzzy PI Controller (SIFPIC) to control the speed of a BLDC motor. The SIFPIC is a simplified control based FLC which utilized only one input control. The employment of SIFPIC, alleviate several problems associates with the design of conventional FLC such as lengthy design cycle, parameters for tuning and complexity of algorithm to implmentat the 
control. Simulation work has been carried out where conventional FLC, SIFPIC and discrete PI controller is used to control the same BLDC motor. From the result, it was shown that SIFPIC shows identical performance with the conventional FLC but with much faster computation and less hectic design cycle.

\section{ACKNOWLEDGEMENTS}

This project is funded by Ministry of Education Malaysia (MOE) under UTM Flagship Project Grant 02G11.

\section{REFERENCES}

[1] Sul, S.-K., Control of electric machine drive systems. Vol. 88. 2011: John Wiley \& Sons.

[2] Finch, J.W. and D. Giaouris, Controlled AC Electrical Drives. Industrial Electronics, IEEE Transactions on, 2008. 55(2): p. 481-491.

[3] Adam, G., A.G. Stan, and G. Livint. Improved Brushless DC Motor Control Algorithm For Reducing Source Current Harmonics. Simulation Study. in ECMS. 2012.

[4] Harnefors, L., S.E. Saarakkala, and M. Hinkkanen, Speed Control of Electrical Drives Using Classical Control Methods. Industry Applications, IEEE Transactions on, 2013. 49(2): p. 889-898.

[5] Shihua, L. and L. Zhigang, Adaptive Speed Control for Permanent-Magnet Synchronous Motor System With Variations of Load Inertia. Industrial Electronics, IEEE Transactions on, 2009. 56(8): p. 3050-3059.

[6] Shun-Chung, W. and L. Yi-Hua, A Modified PI-Like Fuzzy Logic Controller for Switched Reluctance Motor Drives. Industrial Electronics, IEEE Transactions on, 2011. 58(5): p. 1812-1825.

[7] Ayob, S.M., Z. Salam, and N.A. Azli. A Discrete Single Input PI Fuzzy Controller for Inverter Applications. in Industrial Electronics Society, 2007. IECON 2007. 33rd Annual Conference of the IEEE. 2007.

[8] Cupertino, F., A. Lattanzi, and L. Salvatore, A new fuzzy logic-based controller design method for DC and AC impressed-voltage drives. Power Electronics, IEEE Transactions on, 2000. 15(6): p. 974-982.

[9] Ramot, D., et al., Complex fuzzy logic. Fuzzy Systems, IEEE Transactions on, 2003. 11(4): p. 450-461.

[10] Volosencu, C., Control of electrical drives based on fuzzy logic. WSEAS Transactions on Systems and Control, 2008. 3(9): p. 809-822.

[11] Ayob, S.M., N.A. Azli, and Z. Salam, PWM DC-AC converter regulation using a multi-loop single input fuzzy PI controller. Journal of Power Electronics, 2009. 9(1): p. 124-131.

[12] Ibrahim, Z. and E. Levi, A comparative analysis of fuzzy logic and PI speed control in high-performance AC drives using experimental approach. Industry Applications, IEEE Transactions on, 2002. 38(5): p. 1210-1218.

[13] Jung, J.W., et al., Fuzzy PI-type current controllers for permanent magnet synchronous motors. Electric Power Applications, IET, 2011. 5(1): p. 143-152.

[14] McClamroch, N.H. and I. Kolmanovsky, Performance benefits of hybrid control design for linear and nonlinear systems. Proceedings of the IEEE, 2000. 88(7): p. 1083-1096.

[15] Celik, E., et al. An adaptive PI controller schema based on fuzzy logic controller for speed control of permanent magnet synchronous motors. in Power Engineering, Energy and Electrical Drives (POWERENG), 2013 Fourth International Conference on. 2013.

[16] Chowdhuri, S., S.K. Biswas, and A. Mukherjee. Performance Studies of Fuzzy Logic Based PI-like Controller Designed for Speed Control of Switched Reluctance Motor. in Industrial Electronics and Applications, 2006 IST IEEE Conference on. 2006.

[17] Krishnan, P.H. and M. Arjun. Control of BLDC motor based on adaptive fuzzy logic PID controller. in Green Computing Communication and Electrical Engineering (ICGCCEE), 2014 International Conference on. 2014.

[18] Perry, A.G., et al. A new design method for PI-like fuzzy logic controllers for DC-to-DC converters. in Power Electronics Specialists Conference, 2004. PESC 04. 2004 IEEE 35th Annual. 2004.

[19] Srinivas, M.S.S. and K.R. Rajagopal. Fuzzy Logic Based Gain Scheduled PI Speed Controller for PMBLDC Motor. in India Conference (INDICON), 2009 Annual IEEE. 2009.

[20] Ayob, S.M., Z. Salam, and N.A. Azli. Piecewise Linear Control Surface for Single Input Nonlinear PI-Fuzzy Controller. in Power Electronics and Drive Systems, 2007. PEDS '07. 7th International Conference on. 2007.

[21] Ayob, S.M., Z. Salam, and N.A. Azli. Inverter control using a simpilied Fuzzy PI controller. in Power Electronics, Machines and Drives (PEMD 2010), 5th IET International Conference on. 2010.

[22] Byung-Jae, C., K. Seong-Woo, and K. Byung Kook, Design and stability analysis of single-input fuzzy logic controller. Systems, Man, and Cybernetics, Part B: Cybernetics, IEEE Transactions on, 2000. 30(2): p. 303-309.

[23] Perry, A.G., et al. A new design method for PI-like fuzzy logic controllers for DC-to-DC converters. in Power Electronics Specialists Conference, 2004. PESC 04. 2004 IEEE 35th Annual. 2004.

[24] Mohan, N., Electric Drive: An Integrative Approach. 2001, Minesota: John Wiley.

[25] Mohan, N., Undeland, T. M. and Robbin, W. P., Power Electronic-Converters, Applications and Design. third ed. 2003, Hoboken, New Jersey: John Wile \& Sons. 


\section{BIOGRAPHIES OF AUTHORS}

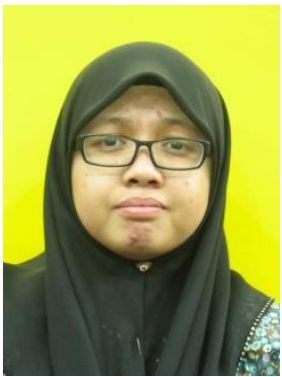

Nur Naqibah Baharudin was born in Negeri Sembilan, Malaysia. She received her first degree in Electrical Engineering and Master in Electrical Engineering in Universiti Teknologi Malaysia in year 2014 and 2018, respectively.

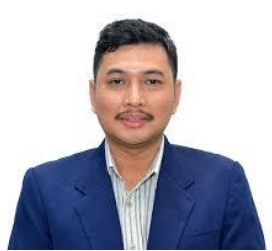

Shahrin Md Ayob was born in Kuala Lumpur, Malaysia in 1979. He obtained his Degree in Bachelor of Electrical Engineering, Master in Electrical Engineering (Power) and Doctor of Philosophy (Electrical) from Universiti Teknologi in year 2000, 2003 and 2010, respectively. Currently he is an associate professor in School of Electrical Engineereing, Faculty of Engineering, Universiti Teknologi Malaysia. He was a chair of Power Electronics Society Malaysia Chapter in year 2017-2018. His current research is in multilevel topology, fuzzy control and electric vehicle. 